\title{
Mechanical Cell Disruption Using Hierarchical Micro-Nano Structures on Nanoporous Alumina Filter
}

\author{
Yong Hun Lee, Eui Don Han, Yong Min Park, Byeong Hee Kim and Young Ho Seo \\ Kangwon National University \\ 1 Gangwondaehakgil, Chuncheon, South Korea, 24341 \\ meat91@kangwon.ac.kr, luvkhy@kangwon.ac.kr, ymp0425@kangwon.ac.kr, kbh@kangwon.ac.kr, mems@kangwon.ac.kr
}

\section{Extended Abstract}

Cell disruption is essential process in molecular biology and biomedical engineering for investigation of DNA, RNA, virus and protein in cell. Generally, there are some methods for cell disruption or cell lysis such as chemical, electrical and mechanical method. [1,2] Chemical cell lysis is method that dissolve cell envelope and nucleus using cell lysis buffer and lysate from this process contains lysis buffer which couldn't know the composition. Electrical and mechanical cell disruption methods required external equipment and shows low cell disruption efficiency. Especially, mechanical cell disruption is easy and quick method and studied using microstructures for increment of cell disruption efficiency. [3, 4] However, most of microstructures such as microchannel or microblade has critical dimension around $3 \mu \mathrm{m}$ and cell could through-out by deformation of its body. [5, 6] In this study, we presents the mechanical cell disruption using hierarchical micro-nano structures on nanoporous alumina filter. Hierarchical micro-nano structures on nanoporous alumina filter was fabricated aluminium wet etching process and multi-step anodic aluminium oxidation process. Pure aluminium sheet (5N, $1 \mathrm{~mm}$ thickness) was mechanical and electro-polished for mirror-like surface. Next, aluminium sheet was dipped in aluminium etchant of $\mathrm{CuCl}_{2}$ base for fabrication of micro-structures. During aluminium etching process, micro-structures were formed by chipping off a grain boundary of aluminium. Multi-step anodic aluminium oxidation process was carried out for fabrication of nano-structures and filter body. Aluminium that formed micro-structures on surface was anodized twice in $0.3 \mathrm{M}$ phosphoric acid aqueous solution of $-5^{\circ} \mathrm{C}$ under $180 \mathrm{~V}$. Formed nanoporous alumina structure was expanded by wet etching process for forming of spike-like nanostructure shape in $0.1 \mathrm{M}$ phosphoric acid aqueous solution of $35^{\circ} \mathrm{C}$. $3^{\text {rd }}$ anodic aluminium oxidation process was carried out for fabrication of filter body under same condition mentioned above for 40hours. Finally, aluminium was removed and barrier layer of nanoporous alumina was opened by wet etching process. For mechanical cell disruption, NIH3T3 fibroblast cells $\left(1 \times 10^{6}\right.$ cells $\left./ \mathrm{ml}\right)$ in PBS (phosphate buffered saline) were injected through hierarchical micro-nano structures on nanoporous alumina filter which assembled with commercial filter holder by air pressure (5bar). Cell disruption efficiency was evaluated by quantification of DNA and protein in lysate. Concentration of DNA and protein were quantified using DNA isolation kit (DNeasy, Quiagen) and Bradford assay, respectively. According to results, $5.1 \pm 1.3 \mu \mathrm{g} / \mathrm{ml}$ of DNA and $46 \pm 11 \mu \mathrm{g} / \mathrm{ml}$ of protein were detected from lysate. In cell disruption process using hierarchical micro-nano structure on nanoporous alumina filter, cell envelope and nucleus were teared by micro-structures and un-teared nucleus by micro-structure was disrupted by nano-structures. This results shows cell envelop disruption of $32 \%$ and cell nucleus disruption of $92 \%$ compared to theoretical value. [7, 8] This work was supported by Basic Science Research Program through the National Research Foundation of Korea (NRF) funded by the Ministry of Education (NRF-2014R1A1A2057692) and also by the Pioneer Research Center Program (NRF-20120009575).

\section{References}

[1] D. Lee, Y. Cho, Transactions of the Korean Society of Mechanical Engineers A, vol. 32, no. 10, pp. 831-835, 2008.

[2] S. Ha, et al., Transactions of the Korean Society of Mechanical Engineers A, vol. 34, no. 12, pp. 1785-1791, 2010.

[3] H. So, et al., ACS Applied Materials and Interfaces, 2014, 6, 6993-6997.

[4] D. Carlo, et al., Lap chip, vol. 3, pp. 287-291, 2003.

[5] R. Brown, J. Audet, Journal of the Royal Society Interface, vol. 5, pp. 131-138, 2008. 
[6] K. Tsukada, et al., Microvascular Research, vol. 61, pp. 231-239, 2001.

[7] A. Leyva, et al., Analytical Biochemistry, vol. 62, pp. 173-179, 1974.

[8] D. Anselmetti, John Wiley \& Sons, Germany, 2009. 